\title{
RANCANG BANGUN MESIN SLATS DOUBLE CUTTING DENGAN SISTEM PENGGERAK PNEUMATIK DAN COMPUTER AIDED MANUFACTURING (CAM)
}

\author{
DESIGN OF DOUBLE CUTTING MACHINE WITH SLATS DRIVE SYSTEMS \\ PNEUMATIC AND COMPUTER AIDED MANUFACTURING (CAM)
}

\author{
Dalmasius Ganjar Subagio \\ Pusat Penelitian Tenaga Listrik dan Mekatronik-LIPI \\ Jl. Sangkuriang Komplek LIPI Gd. 20 Bandung 40135
}

Diterima : 16 April 2012

Direvisi : 21 Mei 2012

Disetujui : 14 Juni 2012

\begin{abstract}
ABSTRAK
Perancangan mesin slats double cutting ini dimaksudkan untuk meningkatkan kapasitas dan kualitas produksi bahan baku pensil pada salah satu perusahaan pensil di Indonesia. Desain mesin menggunakan dua gergaji pada satu motor penggerak sedangkan mekanisme dibuat secara otomatis menggunakan sistim pneumatik yang digabung dengan sistim CAM untuk melakukan proses pemotongan kayu. Mesin ini diharapkan mampu memproduksi irisan kayu sebanyak 650 irisan/jam dengan kualitas baik. Berdasarkan hasil perhitungan, untuk daya motor dibutuhkan 2 x 1,95 HP = 3,9 HP, motor yang digunakan sebesar 5 HP, gaya yang terjadi pada piston lebih kecil dari pada gaya yang terjadi pada gergaji dan tekanan udara yang dibutuhkan untuk mendorong kayu sebesar $\mathrm{Q}=0,0304 \mathrm{~meter}^{3} / \mathrm{menit}$ atau 30,4 liter/menit.
\end{abstract}

Kata kunci : Mesin slats doble cutting, analisa rancang bangun

\begin{abstract}
The design of double slats cutting machine is intended to increase production capacity and quality of raw materials of the pencil industry in Indonesia. Machine was designed using two chainsaws on a motor drive, while mechanism is made automatically using pneumatic system combined with a CAM system to do the wood cutting process. This machine is expected to produce as many as 650 slices of wood slices / hour with good quality. Based on calculations, motor power required is $2 \times 1.95 \mathrm{HP}=3.9 \mathrm{HP}$ using motor of 5 $H P$, the piston force is smaller than that of the saw and the air pressure needed to push the timber is $Q=$ 0.0304 meter $^{3} /$ minute or 30.4 liters / minute.
\end{abstract}

Keywords: cutting machine double slats, engineering analysis

\section{PENDAHULUAN}

Dalam proses produksi pembuatan pensil khususnya pembuatan irisan kayu tidak terlepas dari kebutuhan alat atau mesin, pada gambar 1 merupakan contoh mesin slat single cutting yang ada di pasaran. Kelemahan dari mesin yang ada dipasaran adalah cara kerja mesin yang masih manual karena kayu di dorong oleh operator disamping itu tidak dilengkapi dengan penghisap debu sehingga akan mengganggu saaat produksi.

Penelitian tentang pembuatan pensil penting dilakukan terutama dalam proses pembentukan Slat/irisan kayu, karena dalam proses ini kesulitannya adalah untuk mendapatkan hasil yang presisi untuk setiap proses pemotongan. Dalam rancang bangun mesin slats double cutting bagian yang menentukan sekali adalah daya motor penggerak sehingga perlu dilakukan perhitungan dalam perencanaannya agar tidak terjadi slip pada saat pemotongan.

Disamping daya motor, pemilihan gergaji juga salah satu hal yang menentukan kualitas dan efisiensi produk. Penelitian tentang pensil sebelumnya telah dilakukan oleh beberapa orang, antara lain oleh 1. $\underline{S M}$ 
Jain, G C Sepaha, K C Khare, and V Dubey dengan judul "Silicosis In Slate Pencil Workers". 2 John Rhemrev, Richard Rhemrev, Harvey Smith California Cedar Products Co. Research Dept. Stockton, CA dengan judul The Development of $A$ Moisture Gradient Meter For Pencil Slats [2]

Perkembangan terakhir mengenai penelitian sejenis dilakukan oleh : Cahyo Widayanto dengan judul "Perancangan Mesin Gergaji Kayu Untuk Pengrajin Rak Buku” tahun 2008.

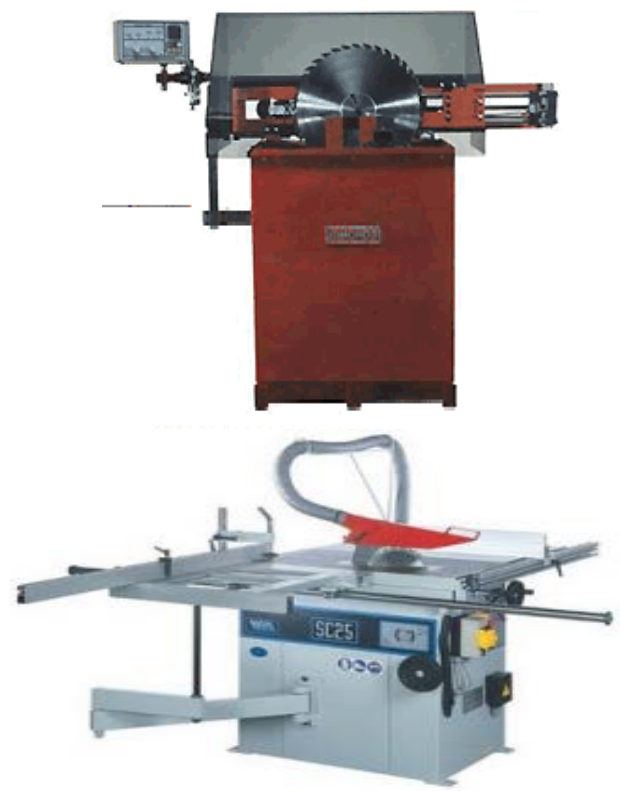

Gambar 1. Mesin Slat Single Cutting

\section{Tujuan}

Tujuan dari Rancang Bangun Mesin Slats Double Cutting adalah untuk mendapatkan desain mesin pengiris agar dapat memperoleh hasil potongan kayu yang presisi untuk setiap proses serta dapat memproduksi dengan output ganda sehingga hasil produksi akan lebih cepat dan presisi.

Perlunya penelitian ini dilakukan karena kebutuhan produksi pensil semakin meningkat sehingga diperlukan peralatan yang lebih cepat untuk memproduksi irisan kayu tersebut. Pada penelitian ini bagian yang dimodifikasi adalah bagian motor penggerak dimana putaran motor difungsikan dari kedua ujungnya seperti dapat dilihat pada gambar 2. Tori dasar yang penting dalam memodifikasi motor tersebut adalah memperhitungkan gaya-gaya yang terjadi akibat pemotongan kayu tersebut.

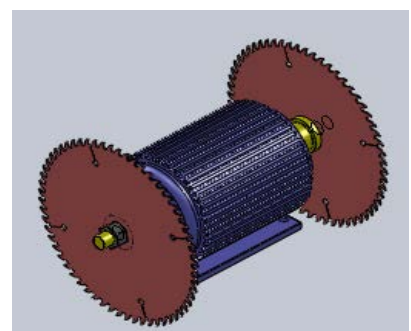

Gambar 2. Modifikasi motor penggerak

\section{BAHAN DAN METODE}

Desain mesin slats double cutting ini dirancang khusus dengan sistim pneumatik untuk mendorong kayu kearah gergaji. Perhitungan dalam makalah ini dibatasi pada perhitungan daya motor, diameter poros gergaji, gaya piston dan kebutuhan udara minimum yang digunakan untuk mendorong balok kayu.

Mesin hasil rancang bangun seperti yang dapat dilihat pada gambar 3 memiliki beberapa kelebihan dibandingkan dengan mesin yang ada di pasaran, diantaranya dapat mengeluarkan hasil irisan sekaligus 2 irisan dalam satu kali proses pemotongan sehingga jumlah produksi dapat mencapai dua kali lipat atau lebih dibandingkan dengan mesin yang single cutting. Selain itu juga mesin ini dilengkapi dengan penghisap debu.
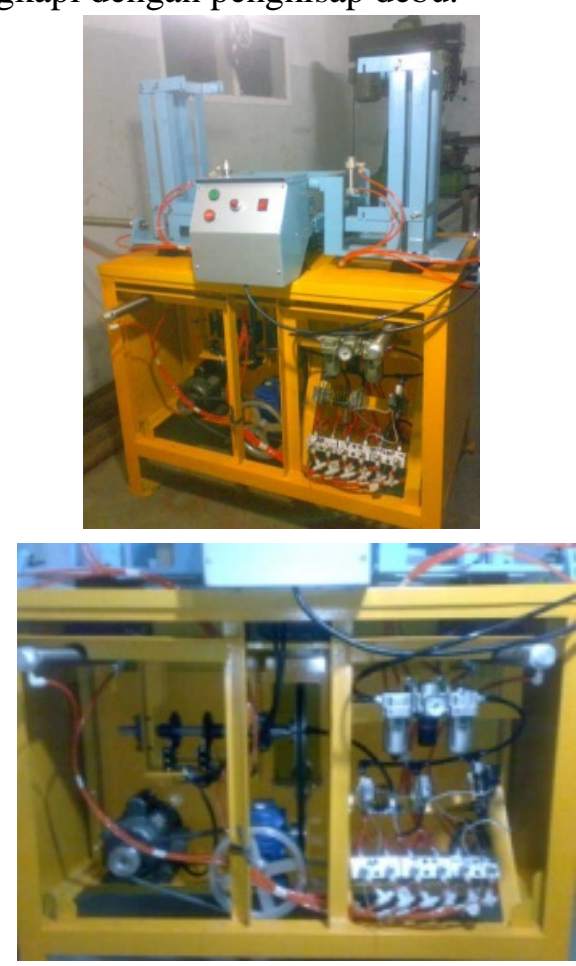

Gambar 3. Mesin Slats Double Cutting 


\section{Gaya Gergaji}

Gaya yang terjadi pada gergaji saat melakukan pemotongan secara teoritis dapat dihitung dengan menggunakan persamaan sebagai berikut :

$\tau_{a}=\mathrm{F} / \mathrm{A}$

$$
\text { dimana : }
$$

$\mathrm{F}$ = gaya gergaji $(\mathrm{kg})$

$\tau_{a}=$ tegangan geser kayu $\left(\mathrm{kg} / \mathrm{cm}^{2}\right)$

$\mathrm{A}=$ luas penampang kayu $\left(\mathrm{mm}^{2}\right)$ (panjang tali busur $\mathrm{x}$ tebal pisau gergaji)

$\mathrm{P}=\mathrm{F} \times v$

$v=\pi$. D.n $/ 1000$.

dimana

$\mathrm{P}=$ daya motor $(\mathrm{kW})$

$v=$ kecepatan $(\mathrm{m} / \mathrm{s})$

$\mathrm{F}$ = gaya gergaji $(\mathrm{kg})$

$\mathrm{P}_{\mathrm{d}}=\mathrm{F}_{\mathrm{c}} \times \mathrm{P}$

dimana :

$P_{d}=$ daya rencana $(\mathrm{kW})$

$f_{c}=$ faktor koreksi $1 \mathrm{~s} / \mathrm{d} 1,5$

$P=$ daya nominal $(\mathrm{kW})$

$T=$ F. r

dimana :

$T=$ momen rencana (kg.mm)

$\mathrm{F}$ = gaya gergaji $(\mathrm{kg})$

$\mathrm{r}=$ jari-jari $(\mathrm{mm})$

$\tau_{a}=\frac{\sigma}{1 \times S f_{2}}$

dimana :

$\sigma_{b}=$ Tegangan tarik $60 \mathrm{~kg} / \mathrm{mm}^{2}$,

$S f_{1}=$ Faktor keamanan 6

$S f_{2}=$ Faktor pengaruh1,3 s/d 3

$\tau_{a}=$ tegangan geser $\left(\mathrm{kg} / \mathrm{cm}^{2}\right)$

$d_{s}=\left\{(5,1 / \tau) \times K_{t} \times C_{b} \times T\right\}^{1 / 3}$.

dimana :

$d_{s}=$ diameter poros

$K t=$ faktor karena beban tumbukan 1,5

$C_{\mathrm{b}}=$ faktor karena beban lentur 1,5

$T=$ momen rencana (kg.mm)

$\tau_{a}=$ tegangan geser yang dizinkan

$\tau_{a}=T /\left(\pi \cdot \mathrm{d}^{3} / 16\right)=5,1 \cdot T / \mathrm{d}^{3}$

\section{Gaya Piston}

Gaya piston yang dihasilkan silinder tergantung pada tekanan udara, diameter silinder, dan gesekan. Gaya piston secara teoritis dihitung dengan menggunakan persamaan sebagai berikut :

$\mathrm{F}=\mathrm{A} \times \mathrm{P}$

dimana :

$\mathrm{F}$ = gaya piston teoritis $(\mathrm{N})$

$\mathrm{A}=$ luas piston yang di pakai $\left(\mathrm{m}^{2}\right)$

$\mathrm{P} \quad=$ tekanan kerja $(\mathrm{Pa})$

$\begin{array}{ccr}\text { Sedangkan } & \text { untuk } & \text { menentukan } \\ \text { diameter piston } & \text { dapat menggunakan }\end{array}$ persamaan sebagai berikut :

$F=P .\left(\pi \cdot d^{2} / 4\right)-\mathrm{R}$

dimana:

$\mathrm{F}$ = gaya piston efektif $(\mathrm{N})$

$\mathrm{P}=$ tekanan kerja (bar/Pa/psi)

$\mathrm{d}=$ diameter piston $(\mathrm{cm})$

$\mathrm{R}$ = gesekan $(\mathrm{N})$ diambil 3-20\% dari gaya

(F)

$\mathrm{N}=\mathrm{m} \times \mathrm{g}$

\section{Aktuator}

Aktuator adalah bagian keluaran untuk mengubah energi suplai menjadi energi kerja. Aktuator pneumatik dibedakan menjadi dua jenis yaitu silinder penggerak tunggal dan silinder penggerak ganda [2].

Silinder kerja tunggal (Single Acting Cylinder) Silinder kerja tunggal mempunyai seal piston tunggal yang dipasang pada sisi pemasukan udara bertekanan. Dengan memberikan udara bertekanan pada satu sisi permukaan piston, sisi yang lain terbuka ke atmosfir. Silinder hanya bisa memberikan gaya kerja ke satu arah. Gerakan piston kembali masuk diberikan oleh gaya pegas yang ada di dalam silinder direncanakan hanya untuk mengembalikan silinder pada posisi awal dengan alasan kecepatan kembali tinggi pada kondisi tanpa beban.

Silinder kerja ganda (Double Acting Cylinder). Silinder penggerak ganda digunakan apabila torak diperlukan untuk melakukan gerakan maju dan mundur. Dengan memberikan udara bertekanan pada satu sisi permukaan piston, sisi yang lain terbuka ke atmosfer. Untuk gaya kerja dua arah, gerakan piston kembali masuk juga diberikan oleh udara yang bertekanan yang diberikan pada sisi yang lain. Dua saluran ini berfungsi sebagai saluran masukan sekaligus juga sebagai saluran pembuangan. 


\section{Pemakaian Udara}

Untuk mengetahui banyaknya konsumsi udara yang diperlukan untuk kerja, dapat dihitung secara teoritis dengan menggunakan persamaan sebagai berikut:

silinder penggerak tunggal :

$\mathrm{Q}=0,785 \times \mathrm{D}^{2} \times \mathrm{h} \times \mathrm{n}$

silinder penggerak ganda :

$\mathrm{Q}=\left\{\left(0,785 \times \mathrm{D}^{2} \times \mathrm{h}\right)\right.$

$\left.+\mathrm{h} \times 0,785 \times\left(D^{2}-d^{2}\right) n \times p k\right\}$

dimana:

$\mathrm{Q}=$ volume udara setiap centimeter langkah (liter/menit)

$\mathrm{D}=$ diameter piston $(\mathrm{mm})$

$\mathrm{d}=$ diameter torak $(\mathrm{mm})$

$\mathrm{h}$ = panjang langkah (mm)

$\mathrm{n}$ = banyaknya langkah setiap menit

$\mathrm{pk}=$ perbandingan kompresi $(\mathrm{kPa})$

$\mathrm{pk}=101,3+$ Tekanan $/ 101,3 \mathrm{kPa}$

\section{HASIL DAN PEMBAHASAN}

Desain yang di buat dalam tulisan ini merupakan desain mesin slats double cutting yang bekerja secara otomatis dengan menggunakan gabungan antara sistim pnematik dan sistim cam. Dibawah ini merupakan poto potongan kayu hasil uji mesin slats double cutting. Hasil irisan merata dengan toleransi rata-rata mencapai 0,1 s/d 0, 2 mm untuk setiap sisi irisan kayu tersebut.
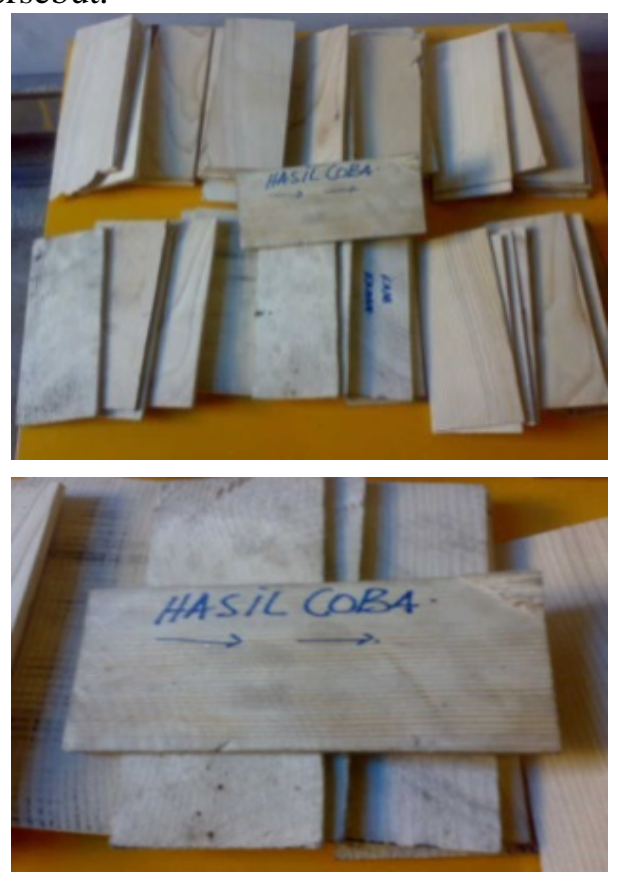

Gambar 4. Potongan kayu hasil uji coba
Sebagai informasi awal data yang telah ditentukan antara lain :

a. Volume balok $=80 \times 80 \times 187 \mathrm{~mm}$

$$
=1196.8 \mathrm{~cm}^{3}
$$

massa jenis kayu $(\rho)=750 \mathrm{~kg} / \mathrm{cm}^{3}$

massa balok kayu $(\mathrm{m})=(\rho) \mathrm{kg} / \mathrm{cm}^{3} \times(\mathrm{V}) \mathrm{m}^{3}$

$750 \mathrm{~kg} / \mathrm{cm}^{3}$ x $1196.8 \mathrm{~cm}^{3}=\mathbf{0 . 8 9 7 6} \mathbf{~ k g}$

Koefisien gesek statik kayu pada besi $=$ 0,4-0,6

b. Circular saw diameter luar $270 \mathrm{~mm}$, diameter dalam $30 \mathrm{~mm}$, tebal badan 1.2 $\mathrm{mm}$, tebal mata gergaji $1,8 \mathrm{~mm}$ dan jumlah mata gergaji 60 buah.

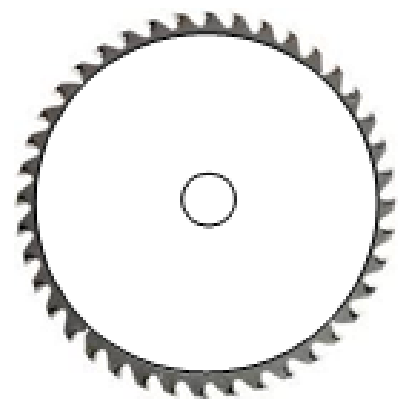

Gambar 5. Circular Saw

\section{Perencanaan Daya Motor}

Daya motor secara teoritis dapat dihitung dengan menggunakan persamaan sebagai berikut : [1-5]

diketahui :

Putaran Motor $=2800 \mathrm{rpm}$,

Tegangan geser kayu $\left(\tau_{a}\right)=0,0104 \mathrm{~kg} / \mathrm{mm}^{2}$

Gaya pada pisau gergaji

$\boldsymbol{\tau}_{a}=\mathrm{F} / \mathrm{A}$ Gambar 6 . Arah potong gergaji

$\mathrm{A}=$ panjang tali busur $\mathrm{x}$ tebal pisau gergaji

$\mathrm{A}=\frac{a}{360} \times \pi \times D \times t$

$\mathrm{A}=\frac{77}{360} \times 3,14 \times 270 \times 1,8$

$\mathrm{A}=0,214 \times 3,14 \times 270 \times 1,8$

$A=326,4$ mm$^{2}$

$\mathrm{F}=\tau_{a \times \mathrm{A}}$

$\tau_{a}=0,0104 \mathrm{~kg} / \mathrm{mm}^{2}$

$\mathrm{F}=0,0104 \mathrm{~kg} / \mathrm{mm}^{2} \times 326,4 \mathrm{~mm}^{2}$

$\mathrm{F}=3,395 \mathrm{~kg}$

Sehingga gaya yang bekerja pada pisau gergaji adalah :

$\mathrm{F}=3,395 \mathrm{~kg} \times 9,8 \mathrm{~m} / \mathrm{s}^{2}=33,27 \mathrm{~N}$

Perhitungan daya motor pada mesin slats double cutting yang direncanakan akan bekerja selama 12 jam dengan putaran motor 2800

rpm. 
$\mathrm{P}=\mathrm{F} \times v$

$v=\frac{\pi \cdot d \cdot n}{60.1000}$

$v=\frac{3,14.270 .2800}{60.1000}$

$v=39,564 \mathrm{~m} / \mathrm{s}$

$\mathrm{P}=\mathrm{F} \times \mathrm{V}$

$\mathrm{P}=33,27 \mathrm{~N} \times 39,564 \mathrm{~m} / \mathrm{s}$

$P=1316,3$ watt $=1,3163 \mathrm{kw}$

Maka daya rencana motor adalah :

$\mathrm{P}_{\mathrm{d}}=\mathrm{f}_{\mathrm{c}} \times \mathrm{P}$

$P_{d}=1,1 \times 1,3163 \mathrm{KW}$

$P_{\mathrm{d}}=1,44793 \mathrm{kw}=1,95 \mathrm{HP}$

untuk satu buah gergaji.

Motor yang digunakan untuk mesin slats double cutting minimal $2 \times 1,95 \mathrm{HP}=\mathbf{3 , 9}$ HP $\leadsto \mathbf{5} \mathbf{H P}$

Momen rencana $T$ (kg.mm)

Bahan poros : St $60=(\sigma \mathrm{b}) 60 \mathrm{~kg} / \mathrm{mm}^{2}$

$T=\mathrm{F} . \mathrm{r}$

$T=3,395 \mathrm{Kg} \times 135 \mathrm{~mm}$

$T=458.325$ kg.mm

Tegangan geser yang dizinkan ( $\tau a)$ adalah

$\tau_{a}=\frac{\sigma b}{S f_{1} \times S f_{2}}$

$\tau_{a}=\frac{60}{6 \times 2}$

$\tau_{a}=5 \mathrm{~kg} / \mathbf{m m}^{2}$

Perhitungan diameter poros $(d \mathrm{~s})$

$d_{s}=\left\langle\left(\frac{5,1}{\sigma a}\right) \times K t \times C b \times T\right\rangle^{1 / 3}$

Sehingga diameter poros didapat :

$d_{s}=\left\langle\left(\frac{5,1}{\sigma a}\right) \times 1,5 \times 1,5 \times 458,325\right\rangle^{1 / 3}$

$=\{1051.855875\}^{1 / 3}$

$d_{s}=10,2 \mathrm{~mm}$

poros yang digunakan pada mesin slats double cutting diameter $\mathbf{2 4} \mathbf{~ m m}$ sehingga aman untuk digunakan. Sedangkan tegangan geser yang terjadi pada poros adalah :

$\tau_{\mathrm{a}}=T /\left(\pi \cdot d^{3} / 16\right)=5,1 \cdot T / d^{3}$

$=5,1 \times 458.325 / 10,2^{3}$

$\tau_{\mathrm{a}}=2337.458 / 1061.208$

$\tau_{\mathrm{a}}=\mathbf{2 , 2} \mathbf{\mathrm { kg }} / \mathrm{mm}^{2}$

Tegangan geser yang terjadi lebih kecil dibandingkan dengan tegangan geser yang diijinkan 2,2 Kg/mm ${ }^{2}<5 \mathrm{Kg} / \mathrm{mm}^{2}$

\section{Gaya yang Terjadi Pada Piston}

Faktor yang menentukan besarnya ukuran pada silinder ditentukan oleh besarnya gaya yang diterima oleh silinder dan panjang langkah yang harus dilakukan oleh silinder untuk memindahkan beban. [6-10]

diketahui :

$(\mathrm{P})=$ tekanan : $800 \mathrm{kPa}=8 \mathrm{bar}=8 \times 10^{5} \mathrm{~N} / \mathrm{m}^{2}$

$(\mathrm{m})=$ massa balok kayu $=\mathbf{0 . 8 9 7 6} \mathbf{~ k g}(\mu)=$

koefisien gesek statik kayu pada besi 0,4-0,6

(h) = panjang langkah torak $=400 \mathrm{~mm}$

$(\mathrm{R})=\operatorname{gesekan}(\mathrm{N})$ diambil $3-20 \%$ dari

Gaya yang terjadi

$$
\begin{aligned}
& \text { Gaya Pada Piston } \\
& \begin{aligned}
\mathrm{N} & =\mathrm{m} \times \mathrm{g}=\mathrm{kg} \times \mathrm{m} / \mathrm{s}^{2} \\
\mathrm{~N} & =\mathrm{m} \times \mathrm{g}=0.8976 \mathrm{~kg} \times 9,8 \mathrm{~m} / \mathrm{s}^{2} \\
& =8.79648 \mathrm{~N} \\
\mathrm{~F} & =\mu \times \mathrm{N} \\
& =0,6 \times 8.79648 \\
& =\mathbf{5 , 2 7 8} \mathrm{N}
\end{aligned}
\end{aligned}
$$

atau :

$$
\begin{aligned}
\mathrm{F} & =(\mathrm{A} \times \mathrm{P})-\mathrm{R} \\
\mathrm{R} & =\operatorname{diambil} 10 \% \text { dari Gaya yang terjadi } \\
\mathrm{R} & =5,278 \mathrm{~N} \times 0.1 \\
& =\mathbf{0 , 5 2 7 8} \mathbf{N} \\
\mathrm{F} & =(\mathrm{A} \times \mathrm{P})-\mathrm{R} \\
\mathrm{A} & =\mathrm{F}+\mathrm{R} / \mathrm{P} \\
& =5,278 \mathrm{~N}+0,5278 \mathrm{~N} / 8 \times 10^{5} \mathrm{~N} / \mathrm{m}^{2} \\
& =0.00000725725 \\
& =\mathbf{7 , 2 5 7} \times 10^{-7} \mathrm{~m}^{2} \\
\mathrm{~F} & =\left(7,257 \times 10^{-7} \mathrm{~m}^{2} \times 8 \times 10^{5} \mathrm{~N} / \mathrm{m}^{2}\right)- \\
0,5278 \mathrm{~N} & =\mathbf{5 , 2 7 8 ~} \mathbf{N}
\end{aligned}
$$

(F) gaya yang terjadi pada piston $(N)<$ dari

(F) gaya yang terjadi pada pisau gergaji $(N)$

\section{Diameter Torak}

$$
\begin{aligned}
\mathrm{A} & =\pi / 4 \mathrm{D}^{2} \\
& =\mathbf{7}, 257 \times 1 \mathbf{1 0}^{-7}=\pi / 4 \mathrm{D}^{2} \\
\mathrm{D}^{2} & =9,21 \times 10^{-7} \times 4 / 3,14 \\
& =6,7 \\
\mathrm{D} & =\sqrt{6,7} \\
& =\mathbf{2 , 6} \mathbf{~ m m}
\end{aligned}
$$

Diameter piston yang digunakan $12 \mathrm{~mm}>$ Diameter piston hasil perhitungan 2,6 $\mathrm{mm}$

\section{Volume Udara yang Diperlukan}

Untuk mengetahui banyaknya konsumsi udara yang diperlukan untuk kerja, dapat dihitung secara teoritis dengan menggunakan persamaan sebagai berikut: 
diketahui :

(D) $=$ diameter piston $=30 \mathrm{~mm}$

(d) = diameter torak $=12 \mathrm{~mm}$

$\mathrm{n}=7,5$ langkah / menit

$\mathrm{pk}=\frac{101,3+\text { tekanan }}{101,3} \mathrm{kPa}$

$\mathrm{pk}=\frac{101,3+800}{101,3} \mathrm{kPa}$

$\mathrm{pk}=8,9 \mathrm{kPa}$

$Q=\left\{\left(0,785 \times D^{2} \times h\right)+h \times 0,785 \times\left(D^{2}-d^{2}\right)\right.$ $\mathrm{n} \times \mathrm{pk}\}$

$=\left\{\left(0,785 \times 0,03^{2} \times 0,35\right)+0,35 \times 0,785 \times\right.$ $\left.\left(0,03^{2}-0,12^{2}\right) 7,5 \times \mathrm{pk}\right\}$

$=\{(0.000247275)+(0.000207711) \times 7,5$

$\mathrm{x} 8,9$

$=(0.000454986) \times 7,5 \times 8,9$

$=0.0304$ meter $^{3} /$ menit

$\mathbf{Q}=\mathbf{3 0 , 4}$ liter $/$ menit

\section{KESIMPULAN}

1. Berdasarkan hasil perhitungan, untuk daya motor dibutuhkan 2 x 1,95 $\mathrm{HP}=\mathbf{3 , 9}$ HP 5 HP

Pada hasil perhitungan poros dengan material ST 60 didapatkan diameter 10,2

2. Sedangkan dalam rancang bangun digunakan poros diameter $24 \mathrm{~mm}$.

3. Tekanan udara yang dibutuhkan untuk mendorong kayu sebesar $(Q)=0,0304$ meter $^{3} /$ menit atau 30,4 liter/menit.

4. Kapasitas produksi yang diharapkan ratarata 650 potong kayu/jam sementara hasil produksi yang didapat dari hasil uji coba mesin slat double cutting sebanyak 800 potong kayu / jam dengan demikian mesin hasil rancang bangun ini sangat efektif digunakan untuk produksi.

\section{DAFTAR PUSTAKA}

[1] G. Takeshi Sato., 2003, Menggambar Mesin,Edisi 10, Pradnya Pratama, Jakarta.

[2] Djoko Wahjono., 2005, Konstruksi Kayu, Universitas Atma Jaya Yogyakarta.

[3] Sularso, MSME., 2002, Dasar Perencanaan dan Pemilihan Elemen Mesin, Edisi 7, PT. Pradya Pratama, Jakarta.
[4] Subagja., 2007, Sains Fisika SMA, Bumi Aksara, Jakarta.

[5] Joseph E. Shigley Larry D. MitChel., 1995, Perencanaan Teknik Mesin, Edisi 4, Erlangga, Ciracas , Jakarta.

[6] E.P. Popov., 1990, Mekanika Teknik, Edisi 2, Erlangga, Ciracas , Jakarta.

[7] Sugihartono., 1985, Dasar-Dasar Kontrol Pnematik, Tarsito,Bandung.

[8] Patient Peter. Pickup Roy. Dan Powell Norman., 1985, Pengantar Ilmu Teknik Pneumika, PT.Gramedia, Jakarta.

[9] Timoshenko. S dan Young. D.H., 1995, Mekanika Teknik, Erlangga, Jakarta. 